\title{
Ramucirumab and other new systemic therapies for hepatocellular carcinoma: still uncovered the problem of Child-Pugh B patients
}

\author{
Markus Wilhelmi^ \\ Medical Clinic I, Gastroenterology and Hepatology, Nutritional Medicine, University Hospital, Frankfurt, Germany \\ Correspondence to: Markus Wilhelmi. Medical Clinic I, Gastroenterology and Hepatology, Nutritional Medicine, University Hospital, Theodor-Stern- \\ Kai 7, 60590 Frankfurt am Main, Germany. Email: dr.markus.wilhelmi@gmail.com.
}

Submitted Mar 08, 2021. Accepted for publication Mar 19, 2021.

doi: $10.21037 / \mathrm{cco}-21-32$

View this article at: http://dx.doi.org/10.21037/cco-21-32

I read with great interest the Editorial Commentary by Longo et al. analyzing the role of ramucirumab as a systemic treatment of hepatocellular carcinoma (HCC) (1).

In addition to mentioning the clinical studies with ramucirumab, the authors rightly point out the relevant data regarding the evidence of efficacy of ramucirumab in HCC patients with a baseline alpha-fetoprotein (AFP) concentration of $400 \mathrm{ng} / \mathrm{mL}$ or higher, which demonstrated for the first time a prognostic marker that is able to effectively identify patients who may benefit from this therapy (2).

As appropriately mentioned by the Authors, in recent years, several systemic agents have demonstrated efficacy in randomized clinical trials for HCC, such as lenvatinib and the atezolizumab-bevacizumab combination in the firstline setting as well as regorafenib and cabozantinib in the second-line setting $(3,4)$.

However, we would like to point out that despite the evidence of efficacy of several systemic therapies, to date there are still subgroups of HCC patients who cannot benefit from these therapies because they were not included in clinical trials.

In particular, this limitation concerns the numerous patients with advanced HCC who have Child-Pugh B liver function, who are regularly excluded from clinical trials.

To date, the only systemic therapy that has demonstrated evidence of efficacy and safety in HCC patients with Child-Pugh B liver function, particularly in those who have experienced sorafenib failure, is metronomic capecitabine (5-7).
Apart from this therapy, for HCC patients with ChildPugh B liver function there are only data on the use of sorafenib, as reported by various clinical practice studies (8). The other aspect that in my opinion deserves to be emphasized concerns the possible prognostic significance of events as surrogate markers of therapeutic efficacy. Unlike sorafenib therapy for which a prognostic significance of adverse events has been reported, no other systemic therapy has ever been reported to have a prognostic significance of adverse events that could guide the maintenance and tailoring of systemic therapy $(9,10)$.

\section{Acknowledgments}

Funding: None.

\section{Footnote}

Provenance and Peer Review: This article was a standard submission to the journal.

Conflicts of Interest: The author has completed the ICMJE uniform disclosure form (available at http://dx.doi. org/10.21037/cco-21-32). The author has no conflicts of interest to declare.

Ethical Statement: The author is accountable for all aspects of the work in ensuring that questions related to the accuracy or integrity of any part of the work are appropriately investigated and resolved.

\footnotetext{
^ ORCID: 0000-0003-0121-0627.
} 
Open Access Statement: This is an Open Access article distributed in accordance with the Creative Commons Attribution-NonCommercial-NoDerivs 4.0 International License (CC BY-NC-ND 4.0), which permits the noncommercial replication and distribution of the article with the strict proviso that no changes or edits are made and the original work is properly cited (including links to both the formal publication through the relevant DOI and the license). See: https://creativecommons.org/licenses/by-nc-nd/4.0/.

\section{References}

1. Longo F, Carrato A. Ramucirumab treatment in hepatocellular carcinoma. Chin Clin Oncol 2020;9:83.

2. Zhu AX, Park JO, Ryoo BY, et al. Ramucirumab versus placebo as second-line treatment in patients with advanced hepatocellular carcinoma following first-line therapy with sorafenib (REACH): a randomised, double-blind, multicentre, phase 3 trial. Lancet Oncol 2015;16:859-70.

3. Ielasi L, Sansone V, Granito A, et al. An update of treatments of hepatocellular carcinoma in patients refractory to sorafenib. Drugs Today (Barc) 2018;54:615-27.

4. Chiang CL, Chan SK, Lee SF, et al. First-Line Atezolizumab Plus Bevacizumab versus Sorafenib in Hepatocellular Carcinoma: A Cost-Effectiveness Analysis.

Cite this article as: Wilhelmi M. Ramucirumab and other new systemic therapies for hepatocellular carcinoma: still uncovered the problem of Child-Pugh B patients. Chin Clin Oncol 2021;10(3):33. doi: 10.21037/cco-21-32
Cancers (Basel) 2021;13:931.

5. Granito A, Marinelli S, Terzi E, et al. Metronomic capecitabine as second-line treatment in hepatocellular carcinoma after sorafenib failure. Dig Liver Dis 2015;47:518-22.

6. Marinelli S, Granito A, Piscaglia F, et al. Metronomic capecitabine in patients with hepatocellular carcinoma unresponsive to or ineligible for sorafenib treatment: report of two cases. Hepat Mon 2013;13:e11721.

7. De Lorenzo S, Tovoli F, Barbera MA, et al. Metronomic capecitabine vs. best supportive care in Child-Pugh B hepatocellular carcinoma: a proof of concept. Sci Rep 2018;8:9997.

8. Granito A, Bolondi L. Non-transplant therapies for patients with hepatocellular carcinoma and Child-PughTurcotte class B cirrhosis. Lancet Oncol 2017;18:e101-12.

9. Granito A, Marinelli S, Negrini G, et al. Prognostic significance of adverse events in patients with hepatocellular carcinoma treated with sorafenib. Therap Adv Gastroenterol 2016;9:240-9.

10. Tovoli F, Ielasi L, Casadei-Gardini A, et al. Management of adverse events with tailored sorafenib dosing prolongs survival of hepatocellular carcinoma patients. J Hepatol 2019;71:1175-83. 